\title{
EL TRATAMIENTO DEL DELITO DE ODIO EN EL DERECHO PENAL ESPAÑOL ${ }^{1}$
}

O TRATAMENTO DO CRIME DE ÓDIO NO DIREITO PENAL ESPANHOL THE TREATMENT OF HATE CRIME IN SPANISH CRIMINAL LAW

\author{
Blanca Martín Ríos ${ }^{2}$
}

Licença CC BY:

Artigo distribuído sob os termos Creative Commons, permite uso e distribuição irrestrita em qualquer meio desde que o autor credite a fonte original.

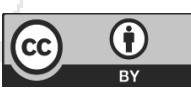

\begin{abstract}
Resumen: El estudio de los límites entre la libertad de expresión y los delitos de odio, cometidos como manifestación de intolerancia, es un tema de gran actualidad. Este trabajo trata de aproximarse al tratamiento jurídico penal español, para lo cual se analizan diversos estudios doctrinales y se toman en consideración documentos de distintos operadores jurídicos. Además de la necesaria pertenencia del sujeto pasivo a uno de los colectivos reconocidos como vulnerables, se examinan los distintos cauces de protección ofrecidos por el Código Penal español. Sin embargo, la tendencia a una aplicación extensiva del Derecho Penal por encima de otras ramas del ordenamiento jurídico, y la existencia de numerosas confusiones terminológicas, generan, además de una injusta pena de banquillo, la demanda de límites y contornos claros que permitan delimitar aquellas conductas intolerables de las amparadas por la libertad de expresión.
\end{abstract}

Palabras clave: Delito de odio; Discurso de odio; Intolerancia; Discriminación; Art. 510 CP.

Palabras clave: Delito de odio; Discurso de odio; Intolerancia; Discriminación; Art. 510 CP.

Resumo: O estudo dos limites entre liberdade de expressão e os crimes de ódio, cometidos como manifestação de intolerância, é uma questão muito atual. Este trabalho procura abordar o tratamento jurídico penal espanhol, para o qual são analisados diversos estúdios doutrinários e considerados documentos de diferentes operadores jurídicos. Além da necessária adesão do sujeito passivo a um dos coletivos reconhecidos como vulneráveis, são examinados os diferentes canais de proteção oferecidos pelo Código Penal espanhol. No entanto, a tendência a uma ampla aplicação do Direito penal sobre outras correntes do ordenamento jurídico, e a existência de inúmeras confusões terminológicas, geram, além de uma injusta sentença judicial, a demanda de limites e contornos claros que permitam delimitar as condutas intoleráveis daquelas amparadas pela liberdade de expressão.

$1 \quad$ Esta investigación se ha realizado al amparo del Proyecto de Investigación: "Protección de las minorías frente a los discursos del odio. La construcción multidisciplinar de la tolerancia desde el Derecho Penal a las políticas públicas", referencia DER2015-66189-P, financiado por el Ministerio de Economía y Competitividad. Resolución de la Secretaría de Estado de Investigación, Desarrollo e Innovación de 6 de mayo de 2016.

2 Doctora en Derecho Penal. Profesora Ayudante en la Universidad Loyola Andalucía, Sevilla, España. Coordinadora del Grado en Criminología. E-mail: blancamartin@uloyola.es., 
Palavras chaves: Crime de ódio; Discurso de ódio; Intolerância; Discriminação; Art. 510 CP.

Abstract: The study of the limits between freedom of expression and hate crimes, committed as a manifestation of intolerance, is a very topical issue. This paper addresses the treatment of hate crime in Spanish criminal law. For this, various doctrinal studies are analyzed and documents from different legal operators are considered. It examines the need for the passive subject to belong to a group that is recognized as vulnerable, and the different channels of protection offered by the Spanish Criminal Code. It is seen that the tendency towards an extensive application of criminal law over other branches of the legal system, and the existence of terminological confusion, have not only generated an unfair public judgement, but have also led to a demand for limits and clear guidelines as to what constitutes intolerable behavior among those protected by freedom of expression.

Key words: Hate crime; Hate speech; Intolerance; Discrimination; Art. 510 CP.

\section{INTRODUCCIÓN}

En la actualidad, y por razones de estudio, placer o trabajo, nos encontramos ante un momento histórico que se caracteriza por el contacto -directo o virtual- con personas de diversas culturas, religiones, naciones, razas o estilos de vida, que posibilita el conocimiento del otro de forma sencilla y accesible. Sin embargo, lejos de promoverse una mayor empatía y respeto por la diversidad, se detecta que la intolerancia en sus distintas manifestaciones (sean delictivas o no), está en pleno auge, produciéndose una radicalización de posturas que conllevan extremismos políticos de distinto signo. En España, el apogeo de estos partidos de signo más radical no es más que la representativa materialización de un clima de intolerancia hacia el diferente, potenciado por las elevadas cifras de inmigración y la crisis económica de los últimos años ${ }^{3}$. Este discurso intolerante está en la base de muchas conductas delictivas, lo que ha conllevado una necesaria y reciente especialización de los agentes con intervención directa en estos delitos, tales como la Fiscalía y la Policía.

En la actualidad, se ha tomado conciencia de la importancia de los delitos cometidos como expresión de una actitud intolerante, por lo que en los últimos años se ha venido produciendo una especialización de las instancias de control social formal e informal, con el objetivo de dar una mejor respuesta a las distintas manifestaciones del problema.

Por un lado, se han creado fiscalías especializadas en delitos de odio ${ }^{4}$. Esta especialización ha provocado notables mejoras en la práctica de la persecución de estas conductas intolerantes, debido principalmente a la cercanía de esta institución con las fuerzas de seguridad y con las ONGS,

3 ALONSO SANZ, Lucía. La protección de los inmigrantes frente al discurso del odio. En: ALONSO, Lucía y VÁZQUEZ, Víctor J. Sobre la libertad de expresión y el discurso del odio. Textos críticos. Sevilla: Athenaica, 2017, pág. 242: Alerta sobre la manipulación del inmigrante, al que se responsabiliza de todos los problemas que aquejan a nuestra sociedad actual (delincuencia, desempleo, crisis económica, etc.), lo que genera un clima de hostilidad que hace que el inmigrante sin recursos sea considerado como el enemigo.

$4 \quad$ La primera de ellas data de 2009, fecha en la que se creó la Fiscalía Provincial de Barcelona al Servicio de Delitos de Odio y Discriminación. Desde entonces, se han ido incrementando el número de fiscalías expertas en esta materia, hasta contar -desde 2013- con una en cada provincia de España. 
ampliando el conocimiento de los ciudadanos sobre los derechos que les asisten y los mecanismos de interposición de denuncias, y consiguiendo, también, paliar un problema especialmente importante en estos delitos, cual es el de la cifra negra ${ }^{5}$, debido al mismo carácter vulnerable del grupo sobre el que recaen estas conductas.

Por otro lado, se ha establecido un Protocolo dirigido a las fuerzas y cuerpos de seguridad, con la intención de que conozcan los datos que, ante la comisión de un delito, deben ser tenidos en cuenta para su inclusión en el atestado, de manera que en él se recoja toda la información necesaria para dilucidar si, en el caso concreto, se trata o no de un delito de odio6.

El nuevo Protocolo de actuación está resultando de gran utilidad al consignar mejor los hechos y determinar los aspectos sobre los que los policías han de prestar especial atención. Antes de su existencia, resultaba difícil dilucidar -en base al atestado- cuándo nos encontrábamos ante un delito susceptible de ser catalogado como delito de odio, ya que las declaraciones de los testigos eran demasiado genéricas y no se tenía en cuenta la motivación del delito, sin que, además, se realizara una correcta inspección ocular que permitiera arrojar datos relevantes para sustentar esta posible motivación.

Además de la especialización de la fiscalía y de la policía, es imprescindible la formación de los demás intervinientes en el sistema de justicia, como abogados o médicos forenses, quienes deben conocer todos los delitos que sancionan determinadas conductas realizadas por un motivo intolerante.

\section{LA REGULACIÓN PENAL DE LOS DELITOS DE ODIO EN EL CÓDIGO PENAL ESPAÑOL}

\subsection{Sistematización del articulado}

Para incorporar los delitos de odio como modalidades delictivas en los textos penales, existen dos técnicas legislativas: o bien reconociendo diferentes preceptos sustantivos que cuentan, como elemento del tipo, con la motivación intolerante o prejuiciosa del sujeto activo, o bien estableciendo una circunstancia agravante genérica de común aplicación a todos los delitos de la parte especial. Nuestro Código penal se decantó, sin embargo, por utilizar ambas opciones: estableció un sistema incriminatorio basado en la existencia de una agravante genérica, contemplada en el apartado $4 .^{\circ}$ del art. 22, aplicable a todo delito cometido por motivos racistas, antisemitas, o en base a otra clase de discriminación referente a la ideología, religión, creencias, etnia, raza o nación, sexo, orientación o identidad sexual, enfermedad o discapacidad; pero recogió también, en el Libro II, una serie de conductas delictivas concretas, que persiguen delitos específicos cometidos por razones de intolerancia7. La doctrina critica, la mejorable redacción

5 GÜERRI FERNÁNDEZ, Cristina. La especialización de la fiscalía en materia de delitos de odio y discriminación. Aportaciones a la lucha contra los delitos de odio y el discurso del odio en España. InDret. Revista para el análisis del Derecho, Barcelona. Enero 2015. Pág. 27.

6 Protocolo de actuación de las Fuerzas y Cuerpos de seguridad para los delitos de odio y conductas que vulneran las normas legales sobre discriminación, Ministerio del Interior, 2015.

$7 \quad$ En virtud del art. $67 \mathrm{CP}$ y del respeto al principio non bis in ídem, la circunstancia modificativa genérica $4 .^{\circ}$ no podrá aplicarse en aquellos delitos que ya valoren ese ánimo intolerante o prejuicioso en la realización de la conducta. 
y sistemática de estos delitos en nuestro Código Penal ${ }^{8}$ que, al decantarse por la configuración autónoma de estos delitos, el legislador podría haber creado una nueva categoría de delitos de odio que recogiera y castigara todas las manifestaciones de este de forma ordenada. Esto, quizás, habría ayudado también a conseguir una mayor comprensión de la naturaleza de estas infracciones por parte de la ciudadanía, que -en demasiadas ocasiones- desconoce qué comportamientos son susceptibles de catalogarse como delitos de odio. En contra de este criterio, ha preferido el legislador recoger, a lo largo del articulado, todas las conductas susceptibles de ser cometidas por motivos de intolerancia, organizándolas en función de los bienes jurídicos protegidos en cada una de ellas.

Actualmente, son muchos los preceptos que, con base en la falta de tolerancia con la diversidad, se encuentran dispersos en nuestro Código Penal, pudiendo diferenciarse en dos grupos: los delitos de odio y los delitos de discriminación?:

En primer lugar, son constitutivos de delitos de odio: Amenazas a un grupo con un mal que constituya delito (art. 170.1 CP), tortura cometida en base a algún tipo de discriminación (art. 174 CP), provocación a la discriminación, odio o violencia contra grupos o asociaciones (art. 510.1 CP), difusión de informaciones injuriosas sobre grupos o asociaciones (art. 510.2 CP), asociación ilícita para promover la discriminación, el odio o la violencia contra las personas, grupos o asociaciones (art. 515.5 CP y 518 CP), delitos contra libertad de conciencia y sentimientos religiosos (arts. 522-525 CP), genocidio (art. 607 CP), delitos de lesa humanidad (art. 607 bis CP). En segundo lugar, y también como manifestación de la intolerancia o el prejuicio, encontramos los delitos de discriminación: Discriminación en el ámbito laboral (art. 314 CP), denegación de prestaciones por un particular encargado de un servicio público o por un funcionario público (art. 511 CP) y la denegación de prestaciones en actividades profesionales o empresariales (art. 512 CP).

En los últimos años solo alguno de estos artículos han sido objeto de reforma. En este estudio analizaremos, únicamente, las manifestaciones más graves de los delitos de odio que han sido modificados de forma relevante por la reciente LO 1/ 2015

Tras esta reforma, el art. 510 se instaura como el precepto que aglutina las conductas fundamentales consideradas de odio, resultando una disposición larga y complicada. Esta norma contempla distintas acciones consideradas merecedoras de sanción siempre que concurran dos elementos: la intolerancia por alguno de los motivos expresamente recogidos en este artículo, y la consideración de grupo vulnerable merecedor de una especial protección.

$8 \quad$ LANDA GOROSTIZA, Jon Mirena. Incitación al odio: evolución jurisprudencial (1995-2011) del art. 510 CP y propuesta "lege data". Revista de Derecho Penal y Criminología, Colombia, n. 7, nota 14. 2012.

9 Esta división de delitos entre delitos de odio y delitos de discriminación, aunque sin aludir a la intolerancia como base común a todos ellos, es realizada también por GÜERRI FERNÁNDEZ, Cristina. La especialización de la fiscalía en materia de delitos de odio y discriminación. Aportaciones a la lucha contra los delitos de odio y el discurso del odio en España. Pág. 6. 


\subsection{Determinación del sujeto pasivo como elemento identificador de estas conductas}

\subsubsection{NUMERUS CLAUSUS VS. NUMERUS APERTUS}

Los artículos del Código penal que sancionan las actuaciones delictivas por razón de intolerancia incluyen como potenciales víctimas de estos delitos los grupos o las partes de determinados grupos. Tras la reforma de 2015 se persigue, también, los delitos cometidos contra ciertas personas individuales seleccionadas debido a su pertenencia a un colectivo. Esto ha suscitado debate en relación a los problemas concursales que plantea, ya que la persecución penal de estas conductas podría haberse solucionado con la introducción de un tipo agravado en cada delito susceptible de cometerse con esta motivación

La pertenencia a ciertos grupos considerados vulnerables está íntimamente ligada al elemento subjetivo especial requerido para la persecución de estas conductas, ya que es necesario, para poder aplicar estos delitos, que, además de con dolo, las conductas delictivas se produzcan con una determinada fundamentación racista, antisemita, o de ideología, religión, creencias, situación familiar, etnia, raza o nación, nacionalidad, sexo, orientación o identidad sexual, razones de género, enfermedad o discapacidad, ya sea por la pertenencia real o figurada al colectivo.

Con relación a esta lista tasada de motivos de intolerancia que pueden fundamentar la aplicación de estos artículos de odio, en especial, de la agravante del art. 22.4 y del art. 510 CP, surgen diversas problemáticas, que se analizan a continuación.

\subsubsection{EXCLUSIVA PROTECCIÓN DE COLECTIVOS CONSIDERADOS VULNERABLES}

En primer lugar, se plantea la doctrina el posible reconocimiento de un sistema de numerus apertus que permita aplicar este artículo a muchas otras manifestaciones de intolerancia hacia la pluralidad. Es cierto que, siendo muy rica la diversidad personal, son muchos más que los recogidos taxativamente en estos artículos los motivos por los que una persona puede ser víctima de intolerancia $y$, en consecuencia, de conductas delictivas. Una asociación con años de experiencia en este campo, Movimiento contra la intolerancia ${ }^{10}$, recoge en sus informes anuales todos los delitos cometidos con base en intolerancias de muy distinta índole: características físicas, económicas, estilo de vida, etc. En consecuencia, plantean la oportunidad de modificar el numerus clausus existente por un numerus apertus, donde tuvieran cabida otras manifestaciones intolerantes, hasta ahora excluidas. Esta defensa tiene su base en la definición de los delitos de odio realizada por la OSCE, que en su apartado final deja abierta la posibilidad de persecución de otras manifestaciones intolerantes al conceptualizarlo como "toda forma de expresión que difunda, incite, promueva o justifique el odio racial, la xenofobia, el antisemitismo u otras formas de odio basadas en la intolerancia"11. En nuestra

10 En su página web, se puede acceder a los distintos Informes Raxen publicados por esta organización: http://www. movimientocontralaintolerancia.com/

11 OSCE n. ${ }^{\circ}$ 4/03, Maastricht, 2 de diciembre de 2003. 
opinión, si bien es cierto que muchos delitos pueden tener su origen en una intransigencia hacia ciertas características o condiciones asociadas a determinadas personas (por ejemplo, el hecho de tener sobrepeso o una corta estatura o el ser estudioso y obtener buenas notas), y aun siendo éste el motivo por el que se cometa la conducta delictiva, esto no debe ser considerado un delito de odio, al no tratarse de colectivos normalmente catalogados como vulnerables. De admitir lo contrario, asumiríamos el riesgo de calificar cualquier conducta como odiosa, ya que la mayoría de los ilícitos penales se cometen con una motivación que sería fácilmente encuadrable como intolerante. De configurarse como numerus apertus, se estaría desvirtuando la finalidad pretendida con estos artículos, diluyéndose su consideración especial al aplicarse a un número elevado de infracciones.

No obstante, sí consideramos que la lista de motivos recogidos en estos artículos es demasiado restringida, y que existen colectivos cuya inclusión sí es necesaria por tratarse de grupos vulnerables. Es el caso de los pobres y de las prostitutas, objeto, con frecuencia, de agresiones por su simple calificación como tales ${ }^{12}$. Se plantea, también, la inclusión de otros elementos, como la gerontofobia, condición que, sin embargo, considero que es más difícil diferenciar en la práctica de otros conceptos penales, como el prevalimiento ${ }^{13}$.

Si bien la restrictiva lista de estos artículos no menciona la protección especial de los pobres, las estadísticas sobre delitos de odio sí que incluyen la aporofobia entre el registro de delitos de odio cometidos cada año ${ }^{14}$. Y ello porque estos estudios tienen la función de analizar las conductas delictivas cometidas en base a estos motivos de intolerancia, con la intención -también- de analizar si se trata o no de colectivos vulnerables, de valorar si sería adecuada o no su inclusión en el articulado y su posible protección por medio del Código penal.

En segundo lugar, partiendo de la adecuación de un sistema restrictivo, de numerus clausus, para la identificación de los motivos objeto de intolerancia, se produce en la práctica la difícil identificación de los colectivos que deben ser protegidos por estos tipos penales.

De acuerdo con la letra de la ley, cualquier persona que sea objeto de conductas delictivas con base en una motivación ideológica, religiosa, etc., podría alegar la comisión de un delito de odio, como ha venido ocurriendo en el último tiempo, lo que ha provocado una constante referencia a una posible comisión de estos delitos ${ }^{15}$.

La mayoría de la doctrina coincide, sin embargo, en que estos tipos delictivos están pensados y reservados para la protección de aquellos grupos considerados vulnerables. Sin embargo, la vul-

12 Numerosa doctrina y profesionales del Derecho se muestran a favor de la inclusión de los pobres como colectivo vulnerable a proteger por estos delitos, al ser, en numerosas ocasiones, objeto de delitos de intolerancia: Entre ellos, GÜERRI FERNÁNDEZ, Cristina. La especialización de la fiscalía en materia de delitos de odio y discriminación. Aportaciones a la lucha contra los delitos de odio y el discurso del odio en España. Pág. 6-7.

13 Cometer el delito contra uno o varios ancianos por el hecho de serlo no tiene por qué implicar siempre, en el fondo, una conducta de intolerancia con las personas de avanzada edad, sino que, en muchas ocasiones puede ser manifestación de prevalimiento o de alevosía, al ser más fácil, en estos casos, la comisión del delito al tener la víctima disminuida o anulada su capacidad de defensa.

14 HATENTO. Observatorio de Delitos de Odio contra las Personas Sin Hogar. Los delitos de odio contra las personas sin hogar. Zerbitzuan: Gizarte zerbitzuetarako aldizkaria = Revista de servicios sociales, Iraila, n. 59, pág. 11347147. Septiembre 2015

15 Éste es el caso, por ejemplo, de los policías y de sus familias hostigados en Cataluña antes, durante y después del referéndum del 1 de octubre de 2017, que incluso llevó a la intervención del entonces Ministro del Interior, Juan Ignacio Zoido en el sentido de que, ante estas acciones, y ante la alusión a una posible comisión de delitos de odio, se haría recaer sobre los culpables todo el peso de la ley. 
nerabilidad es un criterio excesivamente subjetivo que, en la práctica, está provocando problemas de interpretación y de identificación, produciéndose, cada vez más, una ampliación de la lista de colectivos que se consideran ofendidos por estos delitos y que reclaman la intervención penal.

Para evitar dicha ambigüedad, es necesario acudir a criterios objetivos que ayuden a identificar la debilidad de un grupo que la haga merecedora, en estos casos, de protección penal.

\section{REGULACIÓN PENAL DE LOS DELITOS DE ODIO EN EL CÓDIGO PENAL ESPAÑOL}

\subsection{La circunstancia agravante genérica del art. $22.4 \mathrm{CP}$}

La LO 1/2015, de 30 de marzo, mantiene prácticamente sin cambios la agravante genérica del art. 22.4 redactada por nuestro texto de 1995 y modificada por la L.O. 5/2010, de 22 de junio. Se añade, únicamente, la modalidad de discriminación "por razones de género" y se sustituye el término existente de "minusvalía" por el de "discapacidad", considerado menos ofensivo. Así, nuestro Código penal castiga, de manera taxativa, la agravación de la conducta y su consideración como delito de odio cuando se realiza por uno de los motivos tasados en este artículo, motivaciones que coinciden, prácticamente, con las recogidas en el art. 510 CP. Resulta sorprendente que no sean, sin embargo, exactamente las mismas circunstancias a las referidas en estas dos normas, ya que esta agravante del art. 22.4 no incluye la circunstancia de situación familiar que sí incluye el art. 510 CP.

\subsection{El art. $510 \mathrm{CP}$}

El art. 510 CP ha sido objeto de una profunda reformulación por medio de la reforma de 2015, otorgándosele una redacción larga y prolija y convirtiéndolo en el artículo principal y referente de las conductas de odio. Se defiende por la doctrina que esta nueva redacción tiene un doble origen: por una parte, es consecuencia de las sentencias del TC y del TS ${ }^{16}$, que vaciaron de contenido a este artículo y establecieron una línea jurisprudencial favorable a la libertad de expresión que hacía casi imposible la persecución por este tipo de conductas. Por otra parte, surge de la necesaria adaptación de nuestro articulado a dos normativas de ámbito supranacional: el art. 20 del Pacto Internacional de Derechos Civiles y Políticos, que prohíbe toda apología del odio que incite a la discriminación, hostilidad o violencia, y a la Decisión Marco 2008/913/JAI, que expresamente exige la tipificación de determinadas conductas y que las vincula, necesariamente, a unas penas de uno a tres años de prisión como mínimo y a la exclusión de las subvenciones para las asociaciones.

16 Nos referimos a la STC 235/2007, de 7 de noviembre, conocida como caso de la Librería Europa, famosa por declarar la inconstitucionalidad de la negación del genocidio y entenderla amparada por la libertad de expresión, siempre que la misma no conllevara insultos o incitación al odio u hostilidad contra las minorías. En segundo lugar, a la STS 259/2011, que considera atípica la incitación indirecta al entender que el delito de apología del genocidio solo era perseguible si se podía demostrar que, tras las declaraciones vertidas, alguien hubiera actuado en consecuencia, siendo, en caso contrario, también una manifestación de la libertad de expresión. 
Esta reforma, aunque ha mantenido sin cambios gran parte de los artículos existentes ${ }^{17}$, ha llevado aparejada, sin embargo, una profunda concienciación social acerca de la existencia de estos delitos de odio, llevando a la opinión pública a considerar que cualquier conducta intolerante hacia los demás puede incardinarse dentro de estos tipos delictivos. Por el contrario, este artículo no ha gozado de gran predicamento entre la doctrina, que considera mayoritariamente, que su redacción demasiado amplia limita de forma excesiva el derecho a la libertad de expresión, planteando, incluso, su inconstitucionalidad ${ }^{18}$.

\subsubsection{ART. 510.1 CP}

\subsubsection{Art. 510.1. a) CP}

El primer apartado del art. 510.1 castiga el fomento, promoción o incitación pública al odio, hostilidad, discriminación o violencia contra grupos o individuos por motivos racistas, antisemitas, de ideología, religión o creencias, situación familiar, etnia, raza o nación, origen nacional, sexo, orientación e identidad sexual, género, enfermedad o discapacidad. Este artículo, modificado por la LO 1/2015, tiene elementos merecedores de un juicio positivo, aunque mantiene, aún, sin duda, aspectos mejorables.

Así, en primer lugar, destaca como aspecto positivo el cambio en su redacción, solucionando debates doctrinales existentes en torno a su previa regulación. Por una parte, se exige ahora que estas incitaciones sean públicas, tal y como indica la Decisión Marco 2008/913/JAl. Además, se establece también que es posible realizarlas de forma directa o indirecta, acabando así con la amplia discusión doctrinal acerca de la necesidad de que esas instigaciones fueran cometidas directamente. Por otra parte, se ha sustituido el término "provocación" utilizado con anterioridad por los actuales de fomento, promoción o incitación. La eliminación de dicha expresión se considera adecuada al identificarse tanto en nuestra doctrina como en nuestra jurisprudencia el vocablo "provocación" con una determinada categoría dogmática del delito, correspondiente a los actos preparatorios del mismo e, identificándose, por tanto, con un expreso contenido como fase previa a la ejecución del delito. Esto suscitaba el debate en la doctrina acerca de si este término debía equipararse, en este ámbito, con dicho acto preparatorio o si, por el contrario, se trataba de conceptos no asimilables ${ }^{19}$. La nueva redacción de este artículo, al eliminar esta palabra,

17 La LO 1/2015, mantiene prácticamente sin cambios la agravante genérica del art. 22.4 y los arts. 511 y 512 , a los que únicamente añade la modalidad de discriminación «por razones de género». Ninguna modificación sufre, sin embargo, los arts. 170.1 y 314, cuya redacción del CP de 1995 se mantiene inalterable.

18 En este sentido, ALCÁCER GUIRAO, Rafael. Discurso del odio y discurso político", Revista Electrónica de Ciencia Penal y Criminología (RECPC), n. 14-02, pág. 02:1-02:32. 2012. Disponible: http://criminet.ugr.es/ recpc/14/recpc14-02.pdf Consultado: 28 diciembre 2020.

19 EI TS ha llegado a pronunciarse sobre esta polémica, adhiriéndose en su STS 259/2011 a la corriente doctrinal que entendía la provocación del art. 510 en los mismos términos que la establecida en el art. 18.1 y correspondiente a la categoría de actos preparatorios. Recoge una amplia representación de las posiciones doctrinales y jurisprudenciales existentes en relación al término «provocación» establecido en el art. 510 la SAP Baleares, sección 1. ․ㅡ, núm. 312/2013, de 10 de diciembre. 
pone fin a esta discusión, inclinándose por la opinión de que se trata de una conducta diferente e independiente a la dogmáticamente encuadrada dentro de los actos preparatorios.

El nuevo precepto 510 CP contiene también, sin embargo, diversos aspectos que son mejorables. Así, en primer lugar, debemos llamar la atención sobre el excesivo adelanto de la punibilidad que se produce con este delito, justificando la intervención penal en los casos en los que se ha producido una incitación al odio, a la violencia o a la discriminación. De esta manera, por ejemplo, encontramos que, paradójicamente, es posible castigar la conducta de incitación a la discriminación por medio de este primer apartado a) del art. 510 de una manera amplia y genérica, mientras que esa discriminación, en caso de que llegara a ser efectiva, no sería siempre objeto de reproche penal, dado que solo son perseguidas por esta rama del ordenamiento las conductas discriminatorias expresamente tipificadas en los arts. 511 y 512 CP.

La doctrina señala, sin embargo, que esta incorporación excede la mencionada Decisión Marco, que no establece la necesidad de sancionar los actos de promoción, fomento ni incitación directa.

En segundo lugar, se castigan también las conductas que inciten directa o indirectamente a la violencia, determinando la concurrencia de este supuesto el que se trate de un delito de los contemplados en el Código penal como un delito contra la vida, la integridad física o incluso algunos delitos patrimoniales y de daños. El principal problema que plantea esta modalidad es la posible existencia de un concurso de leyes en aquellas ocasiones en las que los actos preparatorios de estas conductas estén también previstos y sancionados penalmente, ya que por medio de este delito se produce un adelanto significativo de la punición. Por otra parte, resulta superflua la inclusión de la incitación al odio, concepto más indeterminado, donde lo que se trata de perseguir es la creación de un estado de aversión a determinados colectivos. En estos casos, no se suele condenar por ello a no ser que provoque una incitación directa a conductas delictivas de discriminación o violencia, resultando innecesaria su tipificación, ya que la misma es contemplada directamente con la regulación de estos conceptos.

Otro aspecto mejorable de la reforma producida en este primer apartado del art. 510 es producto de que se ha realizado una transposición directa de la DM 2008/913/JAI, planteándose que, quizás, habría sido más aconsejable no haber incluido a las personas individuales por su pertenencia a un grupo como posibles sujetos pasivos de estas conductas, reservando estos delitos solo para los ataques a colectivos como delitos de peligro. Para sancionar estas conductas se podría haber creado un tipo específico de amenazas al que le resultara de aplicación la agravante genérica del art. 22.4 CP, resultando de esta forma más gravemente penada la conducta, lo que produciría un resultado más acorde con la finalidad pretendida. En la práctica, la solución adoptada cuando el autor y la víctima son individualizables, más que castigar por este delito de incitación del art. 510, es la de perseguirlo mediante la provocación del correspondiente delito, como ocurrió en el caso del Imán de Fuengirola que publicó un libro donde defendía el castigo físico a las mujeres, así como otros posibles tratos degradantes. 


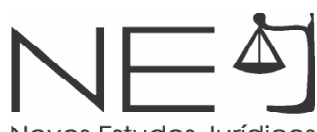

El segundo apartado, b), del art. 510.1 CP castiga la producción, elaboración, posesión, distribución, difusión y venta de material que incite al odio, hostilidad, discriminación o violencia por los motivos discriminatorios señalados en el apartado anterior.

En este párrafo se produce un adelantamiento excesivo de la punición, castigando simplemente la elaboración y distribución de escritos que pudieran fomentar el odio, la hostilidad o la violencia. Muchas de las modalidades que se contemplan en este precepto son, en realidad, formas de participación en la conducta del art. 510.1 a), pudiendo encuadrarse las actividades del editor, del librero, o del director de la publicación con contenido intolerante que incite al odio o a la violencia, como un favorecimiento o incitación a dichas conductas, más aún cuando el primer apartado de este artículo incluye ahora, también, de manera expresa, la incitación indirecta ${ }^{20}$.

La aplicación de este nuevo apartado resulta discutible al entenderse que excede de lo recomendado porla Decisión Marco de 2008, dado que este texto proponía reprochar comportamientos públicos que incitaran a la realización de conductas delictivas, pero no aquellos actos preparatorios para la comisión del delito tales como la elaboración o posesión del material que pudiera incitar al odio o a la discriminación.

Respecto a esta nueva redacción se plantea, también, la afectación del principio de proporcionalidad, dado que no solo establece que la posesión del material intolerante deba ser sancionado, sino que, además, aplica a estos supuestos la misma pena que cuando se realiza la acción considerada como peligrosa, lo que resulta, a todas luces, desproporcionado.

\subsubsection{Art. 510.1. c) CP}

El tercer apartado del art. 510.1 persigue la pública negación del genocidio o enaltecimiento de los autores cuando favorezca el odio, la violencia, hostigamiento o discriminación contra los mismos.

Este párrafo, introducido por la LO 1/2015, incorpora el derogado art. 607.2, pero con una mayor pena que la recogida anteriormente, para castigar los casos de enaltecimiento y justificación de delitos realizados contra la comunidad internacional sólo en los casos en los que se promueva o favorezca la violencia o el odio, tratando de cumplir, con esta exigencia, con la STC 235/2007, de 7 de noviembre, que había declarado su inconstitucionalidad por considerarla contraria a la libertad de expresión.

20 La nueva redacción de este artículo permitiría el castigo de conductas que hasta ahora resultaban impunes, como es el supuesto de la librería Kalki, que vendía publicaciones que legitimaban y justificaban los delitos cometidos por nazis. Si bien estas conductas, de acuerdo con la regulación anterior, resultaban impunes al considerarse que no se producía una incitación directa a actos específicamente delictivos, con esta nueva redacción podrían ser sancionados. 


\subsubsection{ART. 510.2 CP}

El art. 510, en su segundo apartado, sanciona dos acciones diferentes y, ambas, con una pena inferior a las establecidas en el apartado precedente.

\subsubsection{Art. 510.2 a) CP}

La primera de las conductas contempladas en este segundo apartado sanciona las acciones de humillación o menosprecio que lesionen la dignidad de las personas, así como la producción o distribución de material que pudiera lesionarla. Los comportamientos reprochados por este artículo se distinguen, muy sutilmente, de las expresiones amparadas por la libertad de expresión, por lo que se recurre a él con frecuencia para tratar de perseguir cualquier manifestación de burla o humillación de un colectivo. Su aplicación provoca, en consecuencia, un uso desmesuradamente amplio del Derecho penal, fundamentando la persecución de muchas conductas que, en realidad, deberían ser protegidas por la libertad de expresión. Su intervención es, incluso, promovida por personas o colectivos que se sienten humillados o menospreciados, a pesar de no tratarse de los grupos vulnerables a los que se debería limitar la intervención de esta rama del Ordenamiento jurídico. Respecto de este artículo se critica, también, la excesiva punición de estos comportamientos que, si bien podrían ser consideradas formas de colaboración en las conductas del primer apartado del art. 510, se tipifican de manera autónoma para asegurar su castigo como autores. Por otra parte, señala la doctrina la innecesaria tipificación expresa de la producción o distribución de material que pudiera lesionar la dignidad de las personas, ya que este comportamiento se encuentra ahora explícitamente tipificado en el primer apartado del art. 510, letra b.

Como aspecto positivo de la regulación realizada por la reforma podemos destacar la introducción de la dignidad como bien jurídico protegido en este apartado del art. 510. El reconocimiento de la dignidad como objeto de protección en los delitos de odio es motivo de una gran discusión doctrinal, ya que numerosos y reconocidos autores consideran desafortunada esta expresa mención a la misma, defendiendo que el objeto protegido por estos delitos debe ser el honor ${ }^{21}$.

\subsubsection{Art. 510.2 b)}

El segundo apartado del art. 510 CP vuelve a excederse respecto de lo establecido por la Decisión Marco 913/2008 del Consejo de la UE al tipificar expresamente el castigo de todo enaltecimiento o justificación pública de los delitos cometidos con motivos discriminatorios, sin exigir, para poder aplicar el tipo básico, que con ellos se haya promovido la violencia o el odio, como requería la Decisión Marco.

21 Encontramos, sin embargo, en la jurisprudencia de nuestro TC, manifestaciones de un cada vez más importante papel otorgado a la dignidad humana, por ejemplo, por medio de las sentencias 176/1995, 214/1991 y 235/2007, de 7 de noviembre 
Nuestro CP castiga, en este artículo, la simple justificación pública o apología de los delitos cometidos por razones discriminatorias, o de sus responsables, cuando la misma se haya realizado con publicidad. Se trata, por tanto, de un castigo de la apología del odio, que sanciona a aquella persona que con sus declaraciones defiende o justifica la realización de determinados delitos.

La penalidad asociada a estas conductas también es objeto de debate. El tipo básico, que castiga lo que podríamos Ilamar la apología del odio, impone a los autores una pena de prisión de seis meses a dos años y una multa de seis a doce meses, a pesar de que las conductas delictivas que pueden ser justificadas o enaltecidas, siendo delitos comunes, pueden ser muy graves también, como es el caso de las violaciones, asesinatos, torturas, lesiones, etc. Esta sanción resulta significativamente inferior a la establecida en el art. 1 c) para las conductas de justificación o enaltecimiento de delitos contra la comunidad internacional (castigados, como todos los comportamientos recogidos en el primer apartado del art. 510, con una pena de prisión de uno a cuatro años y multa de seis a doce meses).

Si como consecuencia de este comportamiento se promocionara la violencia, hostilidad, odio o discriminación contra los colectivos señalados, esta conducta recibirá, sin embargo, una mayor penalidad. Este artículo es objeto de controversia en nuestra doctrina, ya que se considera que, siendo ésta la conducta exigida por la Decisión Marco, la misma debería constituir el tipo básico del delito y no un tipo agravado, dejando impune el mero enaltecimiento o justificación pública de estos delitos, otorgando, así, un mayor espacio a la libertad de expresión.

\subsubsection{TIPOS CUALIFICADOS DEL ART. 510 CP: ARTS. 510.3 Y 510.4 CP}

El art. 510 prevé dos tipos cualificados, introducidos por la reforma de LO 1/2015, de 30 de marzo. En primer lugar, el art. 510.3 recoge una agravante genérica aplicable a todos los apartados anteriores, castigando con la pena superior en grado cuando los respectivos hechos se hayan realizado por un medio de comunicación, internet o uso de nuevas tecnologías, ya que, al alcanzar a un número mucho más elevado de personas, aumenta considerablemente el riesgo de lesión de los bienes jurídicos protegidos. Este artículo plantea muchos problemas en la actualidad respecto de la difusión y redifusión de contenidos, produciéndose problemas de interpretación sobre cuáles serían los medios de comunicación susceptibles de considerarse como de difusión de contenido, discutiendo la posible valoración de las redes sociales, las webs o foros. En segundo lugar, el art. 510.4 prevé también una cualificación, agravando aquellos supuestos en los que se considere que los hechos realizados en los apartados anteriores resultan idóneos para alterar la paz pública o crear una grave inseguridad en el grupo objeto de la conducta intolerante.

\subsubsection{ConseCUencias Comunes deRIVAdAS DE LOS ARTS. 510.5 Y 510 BIS CP}

La reforma del CP de 2015 que venimos analizando introduce un par de apartados en el art. 510 $\mathrm{CP}$ con consecuencias para todas las conductas contempladas en este artículo. 
En primer lugar, el art. 510.5 establece la pena de inhabilitación especial para profesión u oficio educativo a todos los condenados por alguno de los delitos recogidos en los anteriores apartados de este artículo, sanción especialmente pensada para las profesiones docentes, deportivas y relacionadas con el ocio y tiempo libre de menores.

En segundo lugar, el apartado sexto de este mismo artículo indica que se podrán adoptar medidas para la destrucción, el borrado o la inutilización del material por el que se cometió el delito de incitación al odio o a la violencia, pudiendo acordarse, también, la retirada de contenidos de internet.

Por último, se incorpora también el art. 510 bis, que, en respeto del principio de numerus clausus que determina los delitos en los que se puede exigir responsabilidad jurídica a las empresas, recoge explícitamente la posible responsabilidad de estas entidades por la comisión de los delitos contemplados en los dos primeros apartados del art. 510 CP. La introducción de la responsabilidad de las personas jurídicas es un aspecto novedoso y positivo de esta reforma, previendo el castigo en aquellos supuestos en los que las conductas intolerantes constitutivas de delitos se hayan realizado por medio de una persona jurídica.

\subsection{El art. $607 \mathrm{CP}$}

Por su parte, el art. 607 mantiene únicamente su primer apartado de comisión de genocidio, desapareciendo el segundo de ellos de negación de estas conductas, conforme a la declaración de inconstitucionalidad realizada por la STC 235/2007, de 7 de noviembre. En consecuencia, esta reforma, cambiando su ubicación y su contenido, lo recoge en el art. $510\left(510.1 .^{\circ} \mathrm{c}\right)$ ), exigiendo que la negación del genocidio, para poder ser perseguida, hubiera incitado al odio o a la hostilidad.

\section{VULNERACIÓN DEL PRINCIPIO DE INTERVENCIÓN MÍNIMA DEL DERECHO PENAL EN LA REPRESIÓN ACTUAL DEL DISCURSO DEL ODIO}

\subsection{Aplicación expansiva del Derecho penal, confusión terminológica y pena de banquillo}

En la actualidad, la toma de conciencia de la necesaria intervención estatal frente a la realidad de la intolerancia latente en la realización de muchas conductas -delictivas o no, pero intolerantes-, ha llevado a una aplicación excesiva del Derecho penal, identificando toda actuación intolerante como delictiva. Esto ha conllevado una injerencia desmedida del Derecho penal, que es preciso limitar en respeto al principio de intervención mínima que ha de regir esta rama punitiva de nuestro Ordenamiento jurídico.

En este momento se presenta como necesaria, también, la unificación de criterios existentes en los distintos mecanismos de control formal encargados de la persecución de estas conductas, debiendo adecuarse los elementos de juicio existentes en las distintas fiscalías acerca de qué debe 
entenderse o no como un delito de odio. En este sentido se pronunció también la entonces Fiscal General del Estado, M. ${ }^{a}$ José Segarra, al llamar a una "reflexión sosegada" sobre los delitos de odio, haciendo hincapié sobre la necesidad de establecer unos criterios claros y uniformes para todas las fiscalías, que determinen cuándo nos encontramos o no ante una conducta intolerante con la suficiente entidad como para justificar la intervención penal, que permitan superar el actual debate, conforme al cual es necesario valorar, caso por caso, si existe o no un comportamiento merecedor de sanción ${ }^{22}$.

\subsubsection{Aplicación expansiva del DeREcho Penal}

La regulación anterior de los delitos de intolerancia, recogida en nuestro Código penal de 1995 y vigente hasta la reforma de 2015, establecía, en realidad, una intervención más adecuada del Derecho penal como rama más aflictiva del Ordenamiento Jurídico. La mencionada STC de 235/2007, de 7 de noviembre, lejos de vaciar injustamente de contenido el art. 607 CP, consideramos que reforzó los límites de respeto absoluto a la libertad de expresión como derecho fundamental.

Es tras la reforma operada en 2015 cuando, con la toma de conciencia de la importancia y gravedad de estas manifestaciones de intolerancia, se decide atajar las mismas por medio de un recurso excesivo al Derecho penal, llevando a perseguir prácticamente cualquier conducta intolerante por medio de esta rama del Ordenamiento Jurídico. Esto ha producido una expansión desorbitada e inadecuada del sentimiento de ser víctima de delito de odio, justificando el recurso de distintos grupos de personas a los tribunales en defensa de sus ideologías, creencias, etc. al considerarse humillados o violentados con las bromas, declaraciones o actuaciones, no siempre delictivas, de otras personas. En base a este entendimiento generalizado de que cualquiera puede ser víctima de un delito de odio, se ha producido una tendencia a perseguir todo lo que ofende a alguien, aunque no sea un colectivo vulnerable o en peligro ${ }^{23}$.

Tras el excesivo recurso al Derecho penal realizado durante estos años, en los que hemos visto cómo se presentaban ante el juez penal humoristas, titiriteros, twitteros, etc. por la simple burla o ridiculización de otras personas debido a su raza, ideología o creencias, nos planteamos la urgente necesidad de establecer una respuesta más proporcionada a estas manifestaciones intolerantes ${ }^{24}$.

22 Diversos medios de comunicación se hicieron eco de las declaraciones de la Fiscal General del Estado del lunes 26 de noviembre de 2018, en las que se refería a la necesidad de hacer una «reflexión sosegada» sobre los delitos de odio para otorgarles una respuesta penal «proporcionada, disuasoria y garantista», teniendo como objetivo unificar los criterios de actuación de las fiscalías, estableciendo unos criterios vinculantes de actuación más respetuosos con los criterios establecido por el TUDH para la protección de la libertad de expresión en su delimitación de los delitos de odio.

23 En consecuencia, se ha planteado que las agresiones en Cataluña a los policías o a sus familias podrían entenderse como delito de odio por razones ideológicas, o que el gag del humorista Dani Martín aparentando sonarse con una bandera de España es constitutiva, también, de una conducta de odio hacia el sentimiento de los españoles o un atentado contra los símbolos nacionales.

24 En este sentido, ya el TEDH ha reprochado a España esta punición excesiva, condenándonos en alguna ocasión por la colisión de nuestros artículos con la libertad de expresión. 
En relación con ello, planteaba la entonces Fiscal General del Estado la necesidad de establecer una adecuada ponderación entre lo que debe quedar legitimado por la libertad de expresión, opinión o información, y las conductas constitutivas de delitos de odio, debiendo valorarse, en consecuencia, posibles alternativas a la pena de prisión y una regulación más acorde a la DM 2008/913/JAI.

El recurso a la pena de prisión, tan frecuente en nuestro Derecho penal, no es -sin embargoel más adecuado en estos delitos, sobre todo en cumplimiento de la prevención especial. En este tipo de conductas, basadas en la intolerancia de los sujetos, serían mucho más constructivas y enriquecedoras otro tipo de sanciones con las que se obligaría al infractor a tomar contacto con esa realidad que, muchas veces por desconocimiento, rechaza.

Para ello, podría plantearse como consecuencia jurídica alternativa el trabajo en beneficio de la comunidad en algún ámbito en el que la persona haya mostrado su intolerancia, si bien la dificultad para aplicar este tipo de pena radica en que para su imposición es necesario contar con la autorización del condenado, no pudiendo ser obligado a realizarla.

En caso de que el penado no accediera a esta modalidad de sanción se le podría obligar a participar en cursos de formación o conocimiento de otras razas, creencias o culturas (según el motivo de intolerancia que hubiera generado esta situación), de la misma forma que a los hombres condenados por violencia de género se les ofertan talleres sobre igualdad o a los condenados por delitos de tráfico talleres sobre seguridad vial. Éste es el camino indicado por las Recomendaciones del Consejo de Europa sobre hate speech, que promueven la búsqueda de alternativas menos represoras, tales como las indemnizaciones civiles o las intervenciones administrativas.

Así, por ejemplo, la Comisión Europea contra el Racismo y la Intolerancia (ECRI), en su Recomendación General n. ${ }^{\circ} 15$ sobre Líneas de Actuación para combatir el discurso de odio aconseja a los Estados miembros que

aclaren el alcance y la aplicabilidad de la responsabilidad de Derecho civil o administrativo por el empleo del discurso de odio cuyo objeto sea provocar, o quepa esperar razonablemente que produzca tal efecto, la comisión de actos de violencia, intimidación, hostilidad o discriminación contra aquellos a los que van dirigidas, respetando al mismo tiempo la libertad de expresión y opinión ${ }^{25}$.

Respecto a la aplicabilidad de estas medidas en nuestro Ordenamiento jurídico, CARRILLO DONAIRE se refiere a la larga tradición de aplicación, en el ámbito civil, de la LO 1/1982 de protección civil del derecho al honor, la intimidad personal y la propia imagen.

25 Recomendación General n. ${ }^{\circ} 15$ sobre Líneas de Actuación para combatir el discurso de odio, emanada por la Comisión Europea contra el Racismo y la Intolerancia (ECRI), del Consejo de Europa, adoptada el 8 de diciembre de 2015 (Estrasburgo, 21 de marzo de 2016), p. 10. 
Más difícil resulta encontrar sanciones administrativas en este ámbito, si bien se han comenzado a aplicar, por medio de la Ley del deporte, para tratar de controlar los comportamientos racistas y xenófobos que se venían produciendo en los campos de fútbol ${ }^{26}$.

\subsubsection{Confusión tERMINológiCA: NECESARIA DELIMITACIÓN DE CONCEPTOS}

Uno de los aspectos que consideramos de mayor relevancia en la identificación actual entre discurso de odio y delito de odio es la confusión terminológica existente, que lleva a que cualquier conducta o comentario intolerante sea calificado como delito de odio y perseguido penalmente. La unidad terminológica es de vital importancia a la hora de establecer límites al discurso de odio, debiendo esforzarse todas las entidades que tienen contacto con esta realidad en utilizar los mismos y correctos términos cuando afronten estas conductas y aborden el estudio de la prevención y represión de estos comportamientos

El propio Código Penal utiliza indistintamente los conceptos, induciendo a confusión. Así, por ejemplo, la agravante del art. 22.4 CP alude a "cualquier otra clase de discriminación" cuando, en realidad, sería más apropiado si se refiriese a cualquier otro motivo de intolerancia. La intolerancia puede manifestarse en relación con cualquier delito, que es lo que quiere castigar esta agravante como circunstancia genérica modificativa de la responsabilidad, mientras que la discriminación es una conducta delictiva concreta, manifestación de dicha intolerancia.

El uso correcto de los términos es muy importante para poder graduar la posible responsabilidad de los sujetos intolerantes con la diversidad personal y determinar, en consecuencia, la intervención de las distintas ramas del Derecho, entre ellas la penal. Se ha extendido entre nuestra doctrina la calificación de este discurso como "de odio", atribuyendo la misma consideración a los delitos que tienen en su base este discurso. Sin embargo, no son pocas las confusiones que origina esta terminología, donde, en ocasiones, se identifica discurso de odio con delito de odio o se confunden estos delitos con los cometidos por enemistad o aversión personal contra alguien, eliminando cualquier relación con la intolerancia en razón de la pertenencia a un grupo vulnerable²7.

Por ello, entendemos que resultaría apropiada la sustitución del término "odio" por el de "intolerancia", ya que distintas conductas de humillación, violencia, discriminación, etc., que pueden darse en la práctica, no son más que manifestaciones de un discurso intolerante, consistente en la negación de la dignidad y del derecho a la diversidad. De hecho, la Comisión Europea que afronta estos problemas dentro del Consejo de Europa asumió la lucha contra el Racismo y la Intolerancia en

26 CARRILLO DONAIRE, Juan Antonio. La protección de los derechos frente a los discursos del odio: del Derecho represivo a las políticas públicas antidiscriminatorias. En: ALONSO, Lucía y VÁZQUEZ, Víctor J. Sobre la libertad de expresión y el discurso del odio. Textos críticos. Sevilla: Athenaica, 2017, pág. 26.

27 DE PABLO SERRANO, Alejandro. Límites jurídico-penales del discurso (puro) del odio. Sociedad del desprecio y discurso de odio. En: ALONSO, Lucía y VÁZQUEZ, Víctor J. Sobre la libertad de expresión y el discurso del odio. Textos críticos. Sevilla: Athenaica, 2017, pág. 145-160. DE PABLO se refiere en la página 146 a esta necesidad de distinguir claramente los términos: "No debemos confundir el discurso del odio con los delitos de provocación y los delitos de clima. Tampoco es un delito cometido sobre la base de un sentimiento de odio, motivado por el odio (homicidio por odio, agresiones por odio, injurias por odio); no deben identificarse los delitos de odio ni la circunstancia agravante del odio con el discurso del odio». 
su nomenclatura, considerándolo más adecuado que el de odio ${ }^{28}$. Este discurso de intolerancia tiene diferentes manifestaciones, de diversa gravedad y no todas de carácter delictivo, y, en consecuencia, no pueden ser merecedores de la misma reacción por parte de nuestro Ordenamiento Jurídico.

Así, en primer lugar, podemos encontrar un discurso prejuicioso y estigmatizador, que no tiene por qué ser necesariamente sancionable. En coherencia con ello, se puede pensar y defender -aunque a muchos nos parezca indefendible- en ejercicio de la propia libertad de expresión, la menor habilidad de una determinada raza para la práctica de un concreto deporte, la menor eficacia de cierta etnia en el trabajo o cuestionar que un determinado género trabaje por las tardes en lugar de estar en casa cuidando de sus hijos. Siendo un discurso que prejuzga las cualidades personales y características comportamentales de una persona asociándolas a las que consideramos que son identificativas de un grupo, y por mucho que carezca de base científica, sociológica, política, etc. que lo sustente, es una manifestación de nuestra libertad de expresión que debe, en la mayoría de los casos, quedar fuera de la intervención estatal.

En segundo lugar, se encuentra el discurso discriminador, sancionable en algunos casos, consistente en la defensa de la exclusión de, por ejemplo, los colectivos nombrados por los argumentos mencionados. Es legítimo pensar y defender que cierta raza, etnia o colectivo es menos adecuado que otro para la realización de una determinada tarea, pero no se puede, en base a ello, incitar o realizar una discriminación efectiva en la práctica, ya que esto sí sería objeto de sanción.

Un tercer nivel, más grave, estaría constituido por el discurso de odio, respecto del cual sí que es punible la incitación. Este discurso de odio, sin embargo, no debe identificarse, como ocurre en la práctica, con delito de odio, ya que no todo discurso de odio tiene por qué concretarse en la comisión de una conducta delictiva. La última y más grave manifestación de este discurso de intolerancia estaría constituido por el discurso genocida, que castiga la apología del genocidio ${ }^{29}$.

\subsubsection{LA PENA DE BANQUILLO}

La actual expansión del Derecho penal, facilitada por la confusión terminológica por la que todo comportamiento intolerante es constitutivo de discurso y de delito de odio, así como la pretendida ampliación del sujeto pasivo de estas conductas (eludiendo la condición de grupo vulnerable y acogiendo a cualquier persona que se pueda sentir ofendida, amenazada o humillada por ciertas actuaciones) ha provocado que, en la práctica, se admita a trámite y se solicite la declaración de ciertas personas que, con una estricta interpretación del sentido de la ley, quedarían fuera de su aplicación. De hecho, muchas de las personas citadas son finalmente absueltas o sus casos archivados al entender que no han realizado hechos constitutivos de estos delitos o que los colectivos aludidos no cumplían la condición de vulnerables, por lo que no debían ser objeto de especial protección.

28 Cierta doctrina alude a la discriminación como base de estas conductas, siendo, en realidad, los actos discriminatorios una modalidad delictiva concreta de la intolerancia, términos que no pueden ser equiparados.

29 Estos distintos grados de manifestación de intolerancia es defendida por la entidad Movimiento contra la Intolerancia en distintos materiales, como en su informe Raxen. 
No obstante, con esta actuación se está produciendo una pena de banquillo, en la que, en ocasiones, sabiendo incluso que la persona va a resultar finalmente absuelta de los cargos imputados, se denuncia con el simple objetivo de hacerlo acudir a los tribunales, sobre todo de cara a la opinión pública. El deseo de evitar esta exposición mediática perjudicial para su imagen puede conllevar, también, otra consecuencia (deseada por quienes allí los sitúan), cual es el efecto disuasorio para que no se vuelvan a realizar tales comportamientos (normalmente, humorísticos) con relación a determinados colectivos ${ }^{30}$.

Esta pena de banquillo, producida por la admisión a trámite de estas denuncias, es contraria a nuestro Ordenamiento jurídico, que expresamente establece en el art. 637 LECrim la obligatoriedad de decretar el archivo en aquellos casos en los que la conducta no parece revestir carácter de delito, reservándose la apertura del procedimiento penal solo a aquellos supuestos en los que se cumpla dicho requisito ${ }^{31}$. Así lo defiende Fernández-Gallardo Fernández Gallardo: "el auto de apertura de juicio oral no constituye un acto de mera ordenación formal del proceso, su finalidad es valorar la consistencia de la acusación con el fin de impedir imputaciones infundadas" 32.

\section{CONSIDERACIONES FINALES}

En los últimos años se ha generado una mayor concienciación, tanto social como de los operadores de justicia penal (fiscalía y policía, fundamentalmente), del auge de los discursos intolerantes. Nuestro Ordenamiento Jurídico trata de dar respuesta a esta preocupación por medio de la normativa penal, lo que implica una serie de virtudes y carencias que hemos ido poniendo de manifiesto a lo largo del texto.

La reforma del Código penal operada por la LO 1/2015, de 30 de marzo, realiza una profunda modificación de la regulación de los delitos de odio en nuestro sistema.

Esta nueva redacción contiene aspectos positivos, como la desaparición del término "provocación" del primer apartado del art. 510.1 CP, o la adecuada consideración de la dignidad de la persona como objeto de protección de estos delitos, incorporada por medio del apartado 30 ALMAGRO NOSETE, Jose. Teoría general de la prueba en el proceso penal. En: CGPJ. La prueba en el proceso penal, Cuadernos de Derecho Judicial. Madrid: Consejo General del Poder Judicial, 1992 p. 25: la acusación de un delito es un acto de trascendencia pública que, por las inconveniencias que puede generar, ha de ser adaptada con cautela y seriedad en la acusación. En el mismo sentido, RUIZ VADILLO, Enrique. La actividad probatoria en el proceso penal español y las consecuencias de violarse en ella algún principio constitucional de producirse determinadas irregularidades procesales. En: CGPJ. La prueba en el proceso penal, Cuadernos de Derecho Judicial. Madrid: Consejo General del Poder Judicial, 1992, pág. 53, indica que, para evitar una pena innecesaria de banquillo, la sospecha de comisión de un delito tiene que estar bien fundada.

31 El art. 637 LECrim recoge textualmente: «Procederá el sobreseimiento libre: $10^{\circ}$ Cuando no existan indicios racionales de haberse perpetrado el hecho que hubiere dado motivo a la formación de la causa. $2 .^{\circ}$ Cuando el hecho no sea constitutivo de delito. $3 .^{\circ}$ Cuando aparezcan exentos de responsabilidad criminal los procesados como autores, cómplices o encubridores».

32 FERNÁNDEZ-GALLARDO FERNÁNDEZ GALLARDO. Javier Ángel. Cuestiones derivadas del auto de apertura del juicio oral en el procedimiento abreviado. Anales de Derecho, n. 32, pág. 1-42. 2014. 
segundo del mismo artículo. No obstante, son numerosas las debilidades que aún podemos señalar, encontrando numerosos aspectos mejorables: En primer lugar, es necesaria una correcta delimitación conceptual que permita distinguir los delitos de odio de otras conductas intolerantes, pero para cuya persecución no es necesario que intervenga el Derecho penal, siendo suficiente el recurso a otras ramas del Ordenamiento jurídico, así como una correcta calificación de estas conductas, abogando por la sustitución de delitos de odio por delitos de intolerancia.

En segundo lugar, destaca la mejorable redacción de los artículos reguladores de esta materia, que no en todos los delitos recogen las mismas circunstancias como objeto de intolerancia y olvidan la inclusión de alguna condición importante, como la aporofobia.

En tercer lugar, como uno de los aspectos más relevantes, destaca el innecesario castigo de la incitación indirecta al odio, que sobrepasa las recomendaciones de la Decisión Marco 2008/913/JAI al castigar la mera posesión de contenido intolerante con finalidad de distribución o de facilitación a terceros, lo que provoca una excesiva limitación de la libertad de expresión y un adelanto inadmisible de las barreras punitivas, castigando conductas de peligro abstracto que, en realidad, son constitutivas de actos preparatorios de discriminación, odio, hostilidad o violencia.

Si bien es loable y necesaria la anteriormente mencionada manifestación de nuestra anterior Fiscal General del Estado aludiendo a la necesidad de buscar alternativas a las penas de prisión para estos delitos, es preciso realizar una profunda reflexión acerca de si se está acudiendo de forma desacerbada a esta rama de nuestro Ordenamiento, debiendo establecerse no solo alternativas a la pena de prisión, sino, también, alternativas a la aplicación del Derecho penal.

Así, debemos superar la dualidad de pensamiento que recoge que o bien la conducta es abarcada por la libertad de expresión u opinión o, en caso contrario, es constitutiva de un delito de odio, existiendo vías jurídicas intermedias de posible aplicación. Es necesario, en este punto, reforzar la intervención de las otras ramas del Ordenamiento jurídico, tales como la vía civil en la protección del derecho al honor, o la administrativa, mucho más adecuada para interponerse ante la realización de acciones o emisión de discursos intolerantes que, siendo reprochables, no alcanzan la suficiente entidad como para ser catalogadas como delictivas.

Por último, debemos destacar que la principal dificultad de la regulación y tratamiento del discurso y el delito de odio, que constituye a la vez su principal e ilusionante reto, es que se trata de una materia en construcción, de la que hasta fechas recientes no se ha tomado conciencia de su importancia por medio de los mecanismos de control social formal e informal. Son muchos los avances que se han ido produciendo en esta materia, pero es una realidad que se encuentra aún, y como ocurriera en su día con la violencia de género, tratando de delimitar sus contornos y límites frente a, sobre todo, la libertad de expresión. 


\section{REFERENCIAS DE FUENTES CITADAS}

ALASTUEY DOBÓN, Carmen. Discurso del odio y negacionismo en la reforma del Código Penal de 2015. Revista Electrónica de Ciencia Penal y Criminología (RECPC), n. 18-14, pág. 1-38. 2016. Disponible: http://criminet.ugr.es/ recpc/18/recpc18-14.pdf Consultado: 28 diciembre 2020.

ALCÁCER GUIRAO, Rafael. Discurso del odio y discurso político", Revista Electrónica de Ciencia Penal y Criminología (RECPC), n. 14-02, pág. 02:1-02:32. 2012. Disponible: http://criminet.ugr.es/recpc/14/recpc14-02.pdf Consultado: 28 diciembre 2020.

ALMAGRO NOSETE, Jose. Teoría general de la prueba en el proceso penal. En: CGPJ. La prueba en el proceso penal, Cuadernos de Derecho Judicial. Madrid: Consejo General del Poder Judicial, 1992.

ALONSO SANZ, Lucía. La protección de los inmigrantes frente al discurso del odio. En: ALONSO, Lucía y VÁZQUEZ, Víctor J. Sobre la libertad de expresión y el discurso del odio. Textos críticos. Sevilla: Athenaica, 2017, pág. 241-262.

CARRILLO DONAIRE, Juan Antonio. La protección de los derechos frente a los discursos del odio: del Derecho represivo a las políticas públicas antidiscriminatorias. En: ALONSO, Lucía y VÁZQUEZ, Víctor J. Sobre la libertad de expresión y el discurso del odio. Textos críticos. Sevilla: Athenaica, 2017, pág. 15-38.

CONSEJO DE REDACCIÓN. Los discursos del odio: una amenaza a la construcción democrática de la tolerancia. Revista fomento social, n. 285, pág. 5-27. 2017.

DE PABLO SERRANO, Alejandro. Límites jurídico-penales del discurso (puro) del odio. Sociedad del desprecio y discurso de odio. En: ALONSO, Lucía y VÁZQUEZ, Víctor J. Sobre la libertad de expresión y el discurso del odio. Textos críticos. Sevilla: Athenaica, 2017, pág. 145-160.

FERNÁNDEZ-GALLARDO FERNÁNDEZ GALLARDO. Javier Ángel. Cuestiones derivadas del auto de apertura del juicio oral en el procedimiento abreviado. Anales de Derecho, n. 32, pág. 1-42. 2014.

GÜERRI FERNÁNDEZ, Cristina. La especialización de la fiscalía en materia de delitos de odio y discriminación. Aportaciones a la lucha contra los delitos de odio y el discurso del odio en España. InDret. Revista para el análisis del Derecho, Barcelona. Enero 2015. Disponible: https://indret.com/la-especializacion-de-la-fiscalia-en-materia-de-delitos-de-odio-ydiscriminacion/?edicion=1.15. Consultado: 28 diciembre 2020.

HATENTO. Observatorio de Delitos de Odio contra las Personas Sin Hogar. Los delitos de odio contra las personas sin hogar. Zerbitzuan: Gizarte zerbitzuetarako aldizkaria = Revista de servicios sociales, Iraila, n. 59, pág. 1134-7147. Septiembre 2015.

LANDA GOROSTIZA, Jon Mirena. Incitación al odio: evolución jurisprudencial (1995-2011) del art. 510 CP y propuesta "lege data". Revista de Derecho Penal y Criminología, Colombia, n. 7, pág. 297-346. 2012.

LÓPEZ ORTEGA, Anna Isabel. Análisis y evolución de los delitos de odio en España (2011-2015). Almenara: revista extremeña de ciencias sociales, n. 9, 2017.

OSCE n. ${ }^{\circ}$ 4/03, Maastricht, 2 de diciembre de 2003.

PORTILLA CONTRERAS, Guillermo. La represión penal del "discurso del odio". En: QUINTERO OLIVARES, Gonzalo. Comentario a la reforma penal del 2015, Aranzadi Thomson Reuters, 2015, pág. 717-753.

Protocolo de actuación de las Fuerzas y Cuerpos de seguridad para los delitos de odio y conductas que vulneran las normas legales sobre discriminación, Ministerio del Interior, 2015.

Recomendación General n. ${ }^{\circ} 15$ sobre Líneas de Actuación para combatir el discurso de odio, emanada por la Comisión Europea contra el Racismo y la Intolerancia (ECRI), del Consejo de Europa, adoptada el 8 de diciembre de 2015 (Estrasburgo, 21 de marzo de 2016), p. 10.

RUIZ VADILLO, Enrique. La actividad probatoria en el proceso penal español y las consecuencias de violarse en ella algún principio constitucional de producirse determinadas irregularidades procesales. En: CGPJ. La prueba en el proceso penal, Cuadernos de Derecho Judicial. Madrid: Consejo General del Poder Judicial, 1992. 
SOTO GARCÍA, Mercedes. TEDH - Sentencia de 15.03.2011, Otegi Mondragón C. España, 2034/07 - Artículo 10 del CEDH - Libertad de expresión - límites - delito de injurias contra el Jefe del Estado - Exhortación a la violencia y discurso de odio. Los límites de la libertad de expresión en el debate político, Revista de Derecho Comunitario Europeo, Madrid, n. 42, pág. 575-591. Mayo/agosto 2012.

TERUEL LOZANO, Germán M. La libertad de expresión frente a los delitos de negacionismo y de provocación al odio y a la violencia: sombras sin luces en la reforma del código penal. InDret. Revista para el análisis del Derecho, Barcelona. Octubre 2015. Disponible: https://indret.com/la-libertad-de-expresion-frente-a-los-delitos-de-negacionismo-y-deprovocacion-al-odio-y-a-la-violencia-sombras-sin-luces-en-la-reforma-del-codigo-penal/ Consultado: 28 diciembre 2020.

URÍAS MARTÍNEZ, Joaquín. La libertad de odiar. Delimitando el derecho fundamental a la libertad de expresión, En: ALONSO, Lucía y VÁZQUEZ, Víctor J. Sobre la libertad de expresión y el discurso del odio. Textos críticos. Sevilla: Athenaica, 2017, pág. 39-68. 